\title{
Accuracy of vertebral puncture in percutaneous vertebroplasty
}

\author{
Tomoyuki Noguchi ${ }^{1,2,3,4}$ [ $\cdot$ Koji Yamashita $^{1} \cdot$ Yoshitaka Shida $^{3} \cdot$ Takashi Okafuji $^{3} \cdot$ Ryotaro Kamei $^{1}$. Junki Maehara ${ }^{1}$. \\ Tsuyoshi Tajima ${ }^{3}$
}

Received: 19 April 2021 / Accepted: 28 October 2021 / Published online: 5 November 2021

(c) The Author(s) 2021

\begin{abstract}
Purpose To clarify the accuracy of vertebral puncture of the vertebral tertile area needling (VETERAN) method puncturing the pedicle superimposed on one-third of the width between the lateral vertebral line to the contralateral medial lamina line compared with Cathelin-needle-assisted puncture (CAP) method puncturing using the Cathelin needle as a guide in percutaneous vertebroplasty.

Materials and methods 449 punctures by CAP method and 125 punctures by VETERAN method were enrolled. We compared the puncture accuracy of both methods. We estimated a vertebral estimated tilting ratio (VET-ratio) defined as ratio of the distance between the lateral vertebral line and the contralateral medial laminal line to the distance between the vertebral lateral line and the puncture point measured by computed tomography. We also estimated the procedural items and clinical outcomes.

Results VETERAN method with $100 \%$ of punctures within safe zone (cortical breaches within 2 mm) had significantly higher accuracy than CAP method with $97.8 \%(p<0.01)$ for the $2 \mathrm{~mm}$ incremental evaluation. No cases with a VET-ratio of $36 \%$ or less had cortical breaches. VETERAN method had shorter operative time per puncture $(p<0.01)$ and exposure time per puncture $(p<0.05)$.

Conclusion VETERAN method reduced the occurrence of the inaccurate puncture, operative times, and exposure times. A VET-ratio with $36 \%$ or less is associated with a safe puncture using VETERAN method.

Keywords Vertebroplasty $\cdot$ Punctures $\cdot$ Spine $\cdot$ Needles $\cdot$ Back pain

\section{Abbreviations}

ADL

CAP

CT

ISOP

Activities of daily living

Cathelin-needle-assisted puncture

Computed tomography

Isocenter puncture

IVR-CT Interventional computed tomography

NRS Numeric rating scaling

PVP Percutaneous vertebroplasty

SD Standard deviation

VETERAN Vertebral tertile area needling
\end{abstract}

Tomoyuki Noguchi

tnogucci@gmail.com

Koji Yamashita

yamakou@radiol.med.kyushu-u.ac.jp

Yoshitaka Shida

yshida77@gmail.com

Takashi Okafuji

tokafuji@hosp.ncgm.go.jp

Ryotaro Kamei

kamei@med.kyushu-u.ac.jp

Junki Maehara

ddprogress@hotmail.co.jp

Tsuyoshi Tajima

ttajima@hosp.ncgm.go.jp
1 Department of Radiology, National Hospital Organization Kyushu Medical Center, 1-8-1 Jigyohama, Chuo-ku, Fukuoka City, Fukuoka Province 810-8563, Japan

2 Department of Clinical Research, National Hospital Organization Kyushu Medical Center, 1-8-1 Jigyohama, Chuo-ku, Fukuoka City, Fukuoka Province 810-8563, Japan

3 Department of Radiology, Center Hospital, Center for Clinical Sciences, National Center for Global Health and Medicine, 1-21-1 Toyama, Shinjuku-ku, Tokyo 162-8655, Japan

4 Education and Training Office, Department of Clinical Research, Center for Clinical Sciences, National Center for Global Health and Medicine, 1-21-1 Toyama, Shinjuku-ku, Tokyo 162-8655, Japan 
VET-ratio Vertebral estimated tilting ratio

Vs. Versus

\section{Introduction}

To obliquely puncture the vertebral body through the pedicle has been recommended in percutaneous vertebroplasty (PVP) to avoid the vertebral cortical breaches when puncturing through the transvertebral pedicle parallel to the midline [1]. This oblique puncture, however, is not a simple and easy procedure, and puncture-related complications have been reported; the neurologic complication, the pseudoaneurysm formation due to lumbar injury, the aortic puncture hemorrhage, the spinal epidural, subdural, and subarachnoid hemorrhage [2-7]. Although the frequency of those complications might be low, no respectable studies to investigate the puncture errors have been investigated, neglecting the safety of PVP.

The most common PVP puncture method, the isocenter puncture (ISOP) method [8], is performed as follows. First, the anterior-posterior and lateral projections of the vertebral body are strictly confirmed on fluoroscopy, next the target point of the needle tip placed in the vertebra is set at the isocenter of the fluoroscopy, then the anterior-posterior fluoroscopic view is rotated in the insertion direction, and finally the needle is punctured on-end under fluoroscopy, which is called the bull's-eye modification method [9], and inserted within the vertebral body through the pedicle. This has a wide range of insertion directions. However, the restless patient during puncturing may need to start over repetitively to get back the target point of the vertebral body to the isocenter.

To cover the shortcomings of bone biopsy needle puncturing using the ISOP method, the Cathelin needle used in the local anesthesia is placed as a guide using ISOP method. The insertion route is planned on the images acquired using the Cone-beam computed tomography (CT) or the interventional CT (IVR-CT), and the needle is punctured in parallel with the Cathelin needle [10-12]. This modification is called the Cathelin-needle-assisted puncture (CAP) method. However, performing $\mathrm{CT}$ to plan the insertion route results in the prolonged operative time and exposure time. Another drawback of CAP method was that the Cathelin needle sometimes might not serve as a guide due to displacement, slippage, or overlapping puncture pathways.

We here propose the vertebral tertile area needling method (VETERAN method), which determines the puncture route based on the anatomical structure recognized on the oblique fluoroscopic view without an additional guide device. That is, the anterior-posterior fluoroscopic view is rotated so that the vertebral pedicle is superimposed on one-third of the width between a lateral vertebral line to the contralateral medial lamina line, and then the vertebra is punctured on-end under fluoroscopy using the bull's-eye modification method [9].

However, VETERAN method as well as CAP method have not been objectively validated for safety or risk. Following the process of establishing quality standards for pedicle screw placement in orthopedics, this study was the first to determine the accuracy of vertebral puncture in percutaneous vertebroplasty by comparing VETERAN and CAP methods.

\section{Materials and methods}

\section{Study design}

This retrospective research was approved by our Institutional Review Board, and the need for written informed consent from each patient was waived based on the retrospective nature of this study.

\section{Patients}

Between May 2015 and January 2019 at our hospital, 563 cases were revealed to have unhealed thoracic or lumbar vertebral fractures on spine CT or MRI. Of those, a PVP was performed for 178 cases, whose preoperative status met the following eligibility criteria: they had (1) one or more unhealed vertebral fractures in the 6th thoracic to 5 th lumbar vertebra, (2) severe back pain or a remarkable decrease in activities of daily living (ADLs) due to the vertebral fracture, (3) no active infection, (4) no bleeding diatheses, and (5) they requested a PVP. Of those, 139 cases with 449 punctures made by CAP method from May 2015 to July 2017 (CAP group) and 39 cases with 125 punctures made by VETERAN method from August 2017 to January 2019 (VETERAN group) were enrolled. Demographic information for those two groups was given in Table 1.

\section{PVP operators and equipment}

All procedures were performed in our hospital's angiographic examination room by two or more radiologists including at least one board-certified interventional radiologist who was familiar with the following PVP procedure using biplane fluoroscopic angiography equipment (Axiom Artis dBA; Siemens Healthcare GmbH, Erlangen, Germany) and interventional CT (IVR-CT) (SOMATOM, Sensation, OPEN; Siemens Healthcare GmbH, Erlangen, Germany). 
Table 1 Demographic information of CAP and VETERAN groups

\begin{tabular}{llll}
\hline Item & Unit & CAP group & VETERAN group \\
\hline No. of patients & & 139 & 39 \\
No. of puncture & Total (mean per patient) & $449(3.20)$ & $125(3.28)$ \\
Age & Median (range) year & $82(46-97)$ & $80(39-93)$ \\
Sex & Male/female & $52 / 87$ & $14 / 25$ \\
Vertebral fracture & No. of patients with 1 to 5 & $89 / 39 / 7 / 3 / 1$ & $26 / 9 / 4 / 0 / 0$ \\
& $\quad$ vertebral fractures & & $0(0 \%)$ \\
Neoplastic fracture & No. $(\%)$ of patients & $4(3 \%)$ &
\end{tabular}

No. Number

\section{PVP procedure}

First, the patient was placed in the prone or lateral decubitus position [11] on the examining bed. The area of interest, which was confirmed with fluoroscopy as well as physical examination on the basis of percussion tenderness, was marked and sterilized.

After local infiltration anesthesia was induced, CAP method or VETERAN method was performed. Although the transpedicular approach was usually performed, the transcostovertebral approach for the thoracic vertebra was adopted depending on the operator's decision. Details of CAP and VETERAN methods were described later.

For patients with large vertebral clefts, the test injection of the carbon dioxide gas were performed to know the space of the cleft prior to bone cement injection.

Bone cement (VertaPlex Bone Cement; Stryker) was slowly injected into the vertebra through the bone biopsy needle(s) using a bone cement injector (PCD System; Stryker, Mahwah, NJ) under continuous fluoroscopy. The injection was terminated when the bone cement adequately diffused in the vertebrae, leaked into extravertebral structures, or migrated into veins. The total maximum dose of the bone cement per patient was limited to $12.5 \mathrm{~mL}$, which is the amount contained in one package of the bone cement product. Prophylactic augmentation to adjacent vertebrae [13] was performed for patients whose current vertebral fracture was caused by events other than falling or trauma, had a widened air- or fluid-filled cleft which seemed to be a mass-like distribution after PVP, or had a concomitant preexisting compression fracture in another vertebra [14-16]. Pediculoplasty [17] was also performed in addition to PVP by injecting the bone cement along the needling paths to brace the pedicles of fractured vertebrae after confirming by $\mathrm{CT}$ that the bone biopsy needle passed through the pedicle on CT. After PVP, the distribution of the bone cement was assessed on IVR-CT, and the patient was then held in a supine or lateral decubitus position for $120 \mathrm{~min}$ in the patient's hospital bedroom.

\section{CAP method}

In CAP method, the Cathelin needle used in the local anesthesia was first placed on the vertebral arch as a guide for the bone biopsy needle using ISOP method. Then, a Cone-beam CT or IVR-CT was performed to plan the puncture routes before puncturing. The choice of the two CT modalities depended on operator's decision considering the patient's condition, the number and level of vertebral bodies to be punctured, and the treatment position. If the Cathelin needle might not serve as a guide due to displacement, slippage, or overlapping puncture pathways, the Cathelin needle placement followed by CT scans was repeated. One or more 11- or 13-gauge bone biopsy needles (Osteo-Site Bone Biopsy Needle Set; Cook Medical, Indianapolis, IN) were hammered into the vertebral body by a uni- or bilateral transpedicular or transcostovertebral approach in parallel with the Cathelin needle under fluoroscopic monitoring using the bull's-eye modification method under fluoroscopy. The Cone-beam CT or IVR-CT was performed again to confirm the insertion route of needles after puncturing.

\section{VETERAN method}

In VETERAN method, the anterior-posterior fluoroscopic view was rotated about 10 to 40 degrees along the body axis so that the vertebral pedicle was superimposed on one-third of the width between a lateral vertebral line to the contralateral medial lamina line as determined by visual judgement on the oblique fluoroscopic view. In the case of transcostovertebral approach for the thoracic vertebra, the costovertebral space was superimposed on one-third of the width between a lateral vertebral line and the contralateral medial lamina line. Then, the bone biopsy needle was hammered into the vertebral body by a uni- or bilateral puncturing with the transpedicular or transcostovertebral approaches using the bull's-eye modification method under fluoroscopy. A Cone-beam CT or IVR-CT was performed once to confirm the insertion route of the needles after puncturing. 


\section{Estimation of the accuracy of the needle insertion course}

To retrospectively assess the accuracy of the needle insertion course in the Cone-beam CT or IVR-CT images acquired after puncturing, the canal encroachment of the needles were measured and classified using Gertzbein and Robbins classification scores which were commonly used for the assessment of the pedicle screw placement in spinal surgery based on CT as follows [18].

Grade A: the screw completely within the pedicle.

Grade B: pedicle cortical breach by $2 \mathrm{~mm}$ or less.

Grade C: pedicle cortical breach by $4 \mathrm{~mm}$ or less.

Grade D: pedicle cortical breach by $6 \mathrm{~mm}$ or less.

Grade E: pedicle cortical breach by more than $6 \mathrm{~mm}$.

Grades A and B were considered "clinically acceptable", and those Grades C-E had a significant deviation from the intended trajectory and were also considered "inaccurate" (Fig. 1) [19]. The difference in the occurrence of the vertebral cortical breaches judged as "inaccurate" or "clinically acceptable" between the VETERAN and CAP groups was determined by the Chi-square test.

We measured the puncture angle, which was the inclination towards the midline, as an indicator of safe or warning vertebral puncture. In addition, we also measured the vertebral estimated tilting ratio (VET-ratio) as a surrogate index to the puncture angle. VET-ratio was the distance ratio between a lateral vertebral line to the contralateral medial lamina line and the vertebral lateral line to the puncture point (Fig. 2). The puncture angle and VET-ratio were measured on the Cone-beam CT or IVR-CT images acquired after puncturing.

\section{Assessment of clinical outcome}

Each of the patients performed a self-assessment of his or her back pain on a scale of 0 to 10 (with 0 indicating no pain and 10 indicating the maximum imaginable pain) known as the pain numeric rating scale (NRS) scores [12, 20]. We determined the patients' mobility ADL scores using the following five-point scale, which is a modification of Yokoyama's ADL scores [12, 21]: 0 points = complete independence; 1 point = light assistance, being able to walk with walking equipment; 2 points $=$ moderate assistance, needing a wheelchair for locomotion; 3 points = major assistance, mostly staying in bed and being able to sit upright at 60 to 90 degrees; and 4 points = total assistance, mostly staying in a bed-ridden state and being upright under 60 degrees.

The patients' pain ratings and mobility scores were estimated 1 day before PVP and on the 7th day after PVP. If there were any lost or missing score data 7 days after PVP, we used the scores that were rated closest to the date of the lost data. We also assessed post-PVP complications and adverse events among the patients. All data were identified using our institution's Hospital Information System.

We estimated the differences between CAP and VETERAN groups with regard to other items including the procedural success rates, the number of the uni- or bilateral puncture, occurrence of bone cement leakage, pulmonary emboli, and cardiac dysfunction by the Chi-square test, the
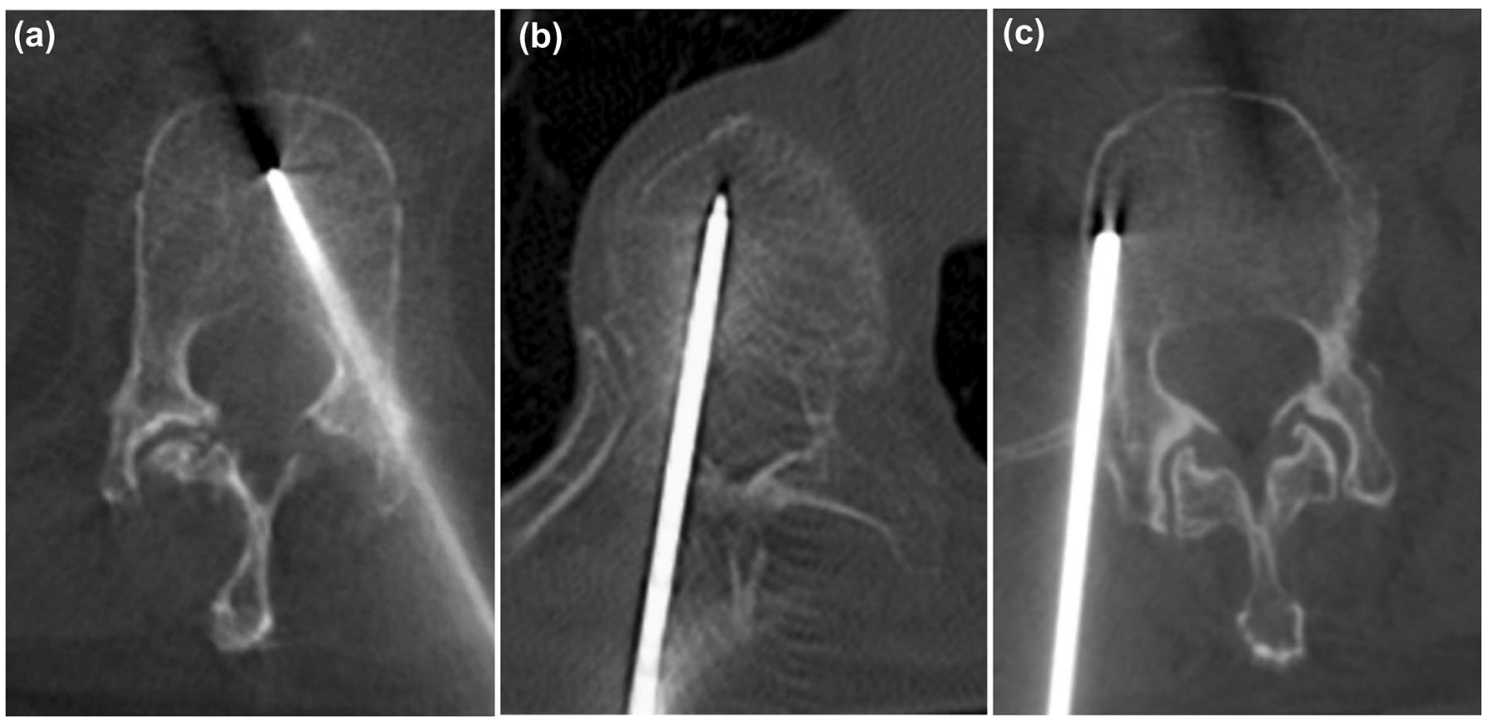

Fig. 1 An IVR-CT image (a) and Cone-beam CT images (b and $\mathbf{c}$ ) of the vertebral body after the bone biopsy needle insertion. Cases $\mathbf{a}, \mathbf{b}$, and $\mathbf{c}$ are Grade A (no cortical breach) in medial breaches, Grade B (the cortical breach with $2 \mathrm{~mm}$ or less) in medial breaches, and Grade
$\mathrm{C}$ (the cortical breach with $4 \mathrm{~mm}$ or less) in lateral breaches, respectively, according to Gertzbein and Robbins classification scores based on CT commonly used to assess the pedicle screw placement in spinal surgery 


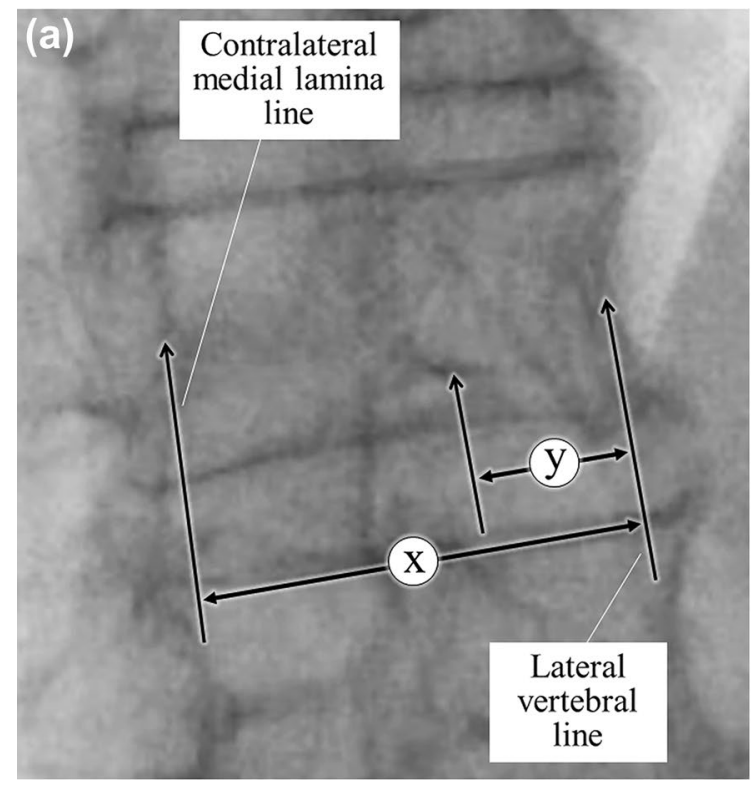

Fig. 2 A left anterior oblique fluoroscopic view of the lumbar vertebral body before puncturing (a) and an IVR-CT image of the lumbar vertebral body after the insertion of the bone biopsy needle (b). The right, center, and left vertical arrows in (a) and (b) indicate the lateral medial lamina line, the puncture point, and the contralateral vertebral line, respectively. Vertebral estimated tilting ratio (VET-ratio) is

operative time per puncture and radiation exposure time per puncture, Cone-beam CT exposure dose, the number of Cone-beam CT scans, IVR-CT exposure dose using the dose length product (DLP), the number of IVR-CT scans, the bone cement volume per vertebra, pain NRS scores at 1 day before PVP and on the 7th day after PVP, and mobility ADL scores at 1 day before PVP and on the 7th day after PVP by the Mann-Whitney's $U$ test.

\section{Statistical analysis}

The statistical analysis was properly performed using Excel 2013 (Microsoft, Seattle, WA) with an add-in software Statcel-3 [22], regarding the correlation analysis using Pearson's correlation coefficient test, the univariate analysis using Mann-Whitney's $U$ test or the Chi-square test. The level of significance was set at $P<0.05$ for all tests.

\section{Results}

\section{Estimation of the accuracy of the needle insertion course}

Table 2 showed the number distribution of the punctures of Gertzbein and Robbins classification scores for CAP and VETERAN groups. The "clinically acceptable "accuracy of

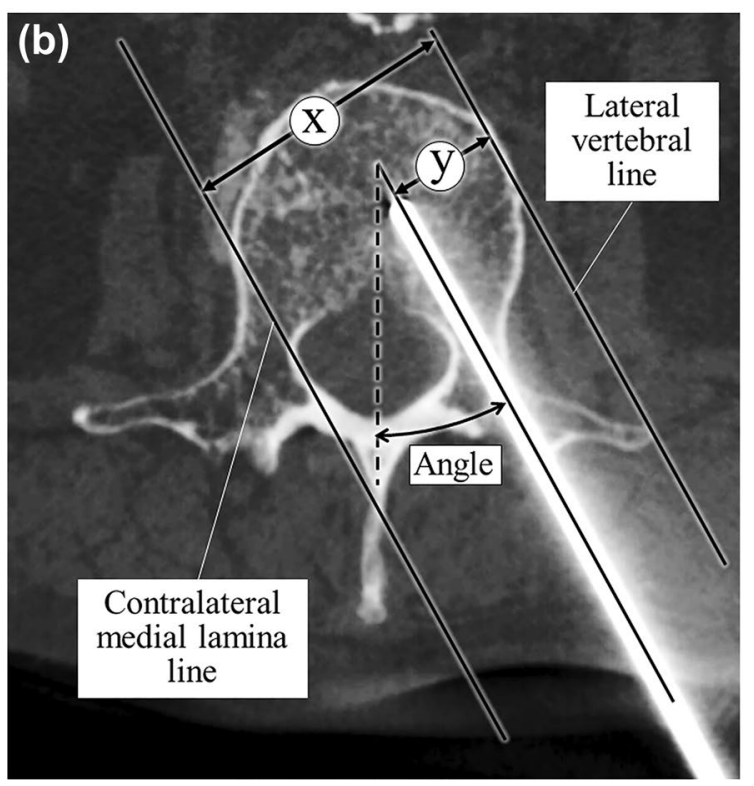

equal to $y / x(\%)$, where ' $x$ ' represents the distance between the lateral vertebral line and the contralateral medial lamina line and ' $y$ ' represents the distance between the vertebral lateral line and the puncture point shown in (a) and (b). VET-ratio should be 33\% in VETERAN method

needle puncture (Grades A and B) in CAP and VETERAN groups was $97.8 \%$ and $100 \%$, respectively. Statistical analysis showed VETERAN group had statistically significant superiority $(P<0.01)$ in "clinically acceptable" accuracy compared with CAP group.

Table 3 showed the averages and ranges of the needle puncture angles for CAP and VETERAN groups. When CAP and VETERAN groups were combined, the ranges of the puncture angles in Grade A, the medial cortical breaches in Grade B-D, and the lateral cortical breaches in Grade B-C were 3-42, 14-40, and 9-33 degrees, respectively.

Table 4 showed the averages and ranges of the VET-ratios for CAP and VETERAN groups. When CAP and VETERAN groups were combined, the ranges of VET-ratios in Grade A, the medial cortical breaches in Grade B-D, and the lateral cortical breaches in Grade B-C were 4-50\%, 37-63\%, and 6-35\%, respectively.

\section{Procedural items and clinical outcomes}

Table 5 showed the results of the procedural items and clinical outcomes. Both CAP and VETERAN groups had $100 \%$ procedural success rates. The VETERAN group had significantly shorter operative time per puncture (with the mean \pm SD being $29 \pm 8$ vs. $24 \pm 9$, respectively, $p<0.01$ ) and shorter exposure time per puncture (with the mean \pm SD being $10 \pm 3$ vs. $8.8 \pm 3.4$, respectively, $p<0.05$ ) than CAP 


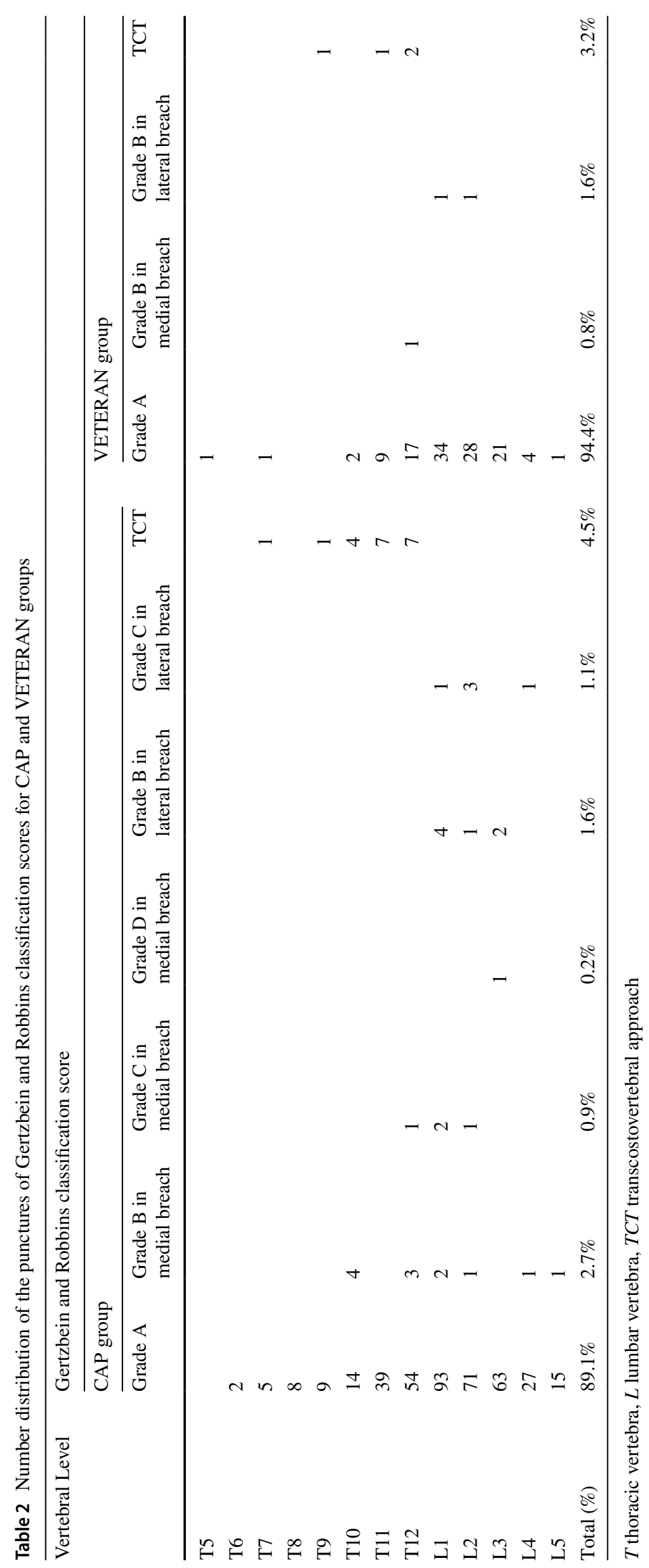




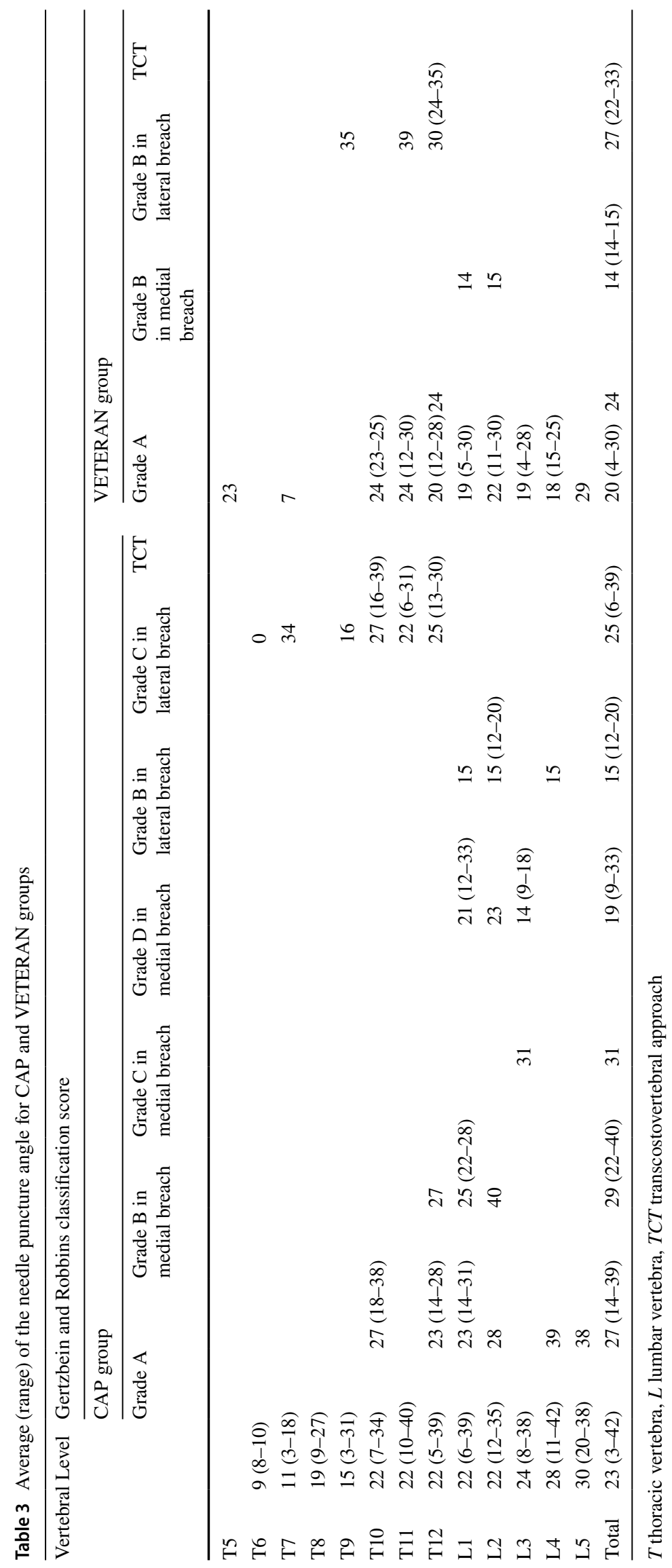




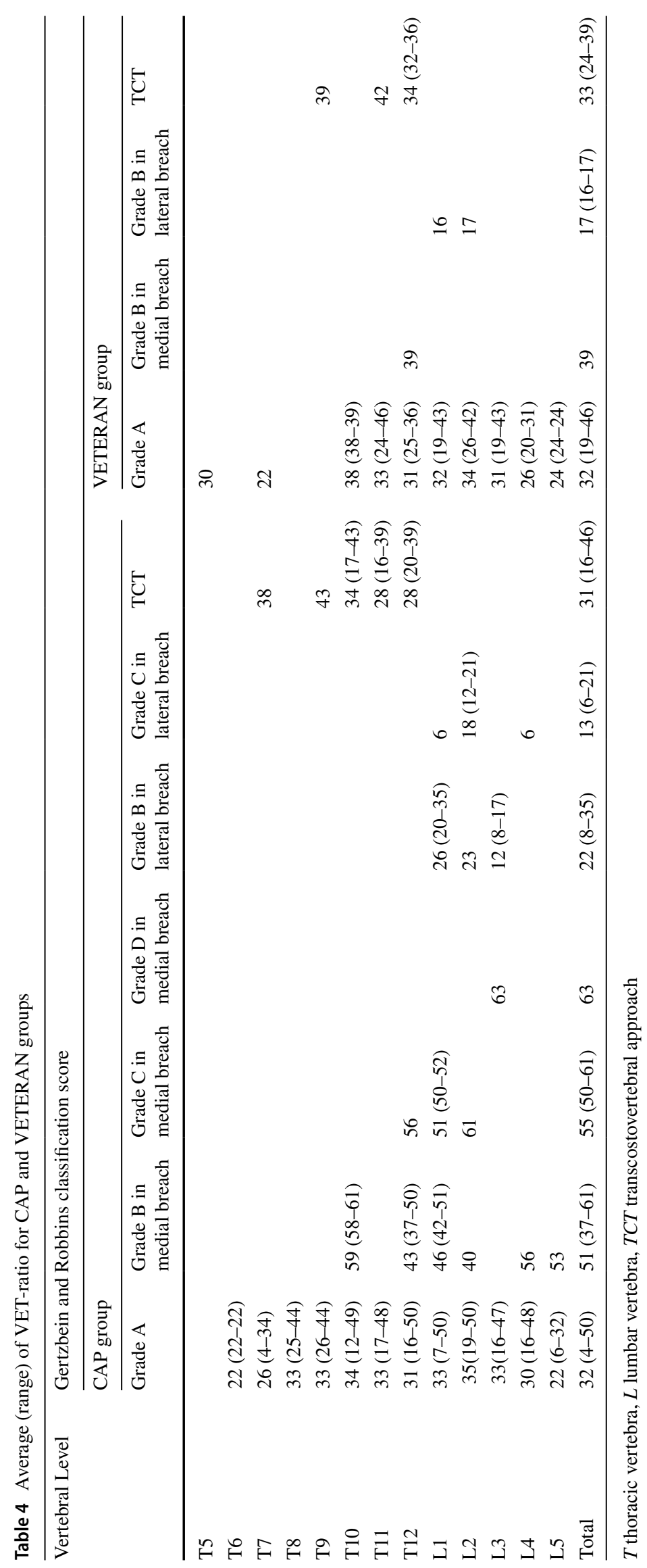


Table 5 Results of the procedural items and clinical outcomes

\begin{tabular}{|c|c|c|c|c|}
\hline Items & Unit & CAP group & VETERAN group & $p$ value \\
\hline Procedural success rate & $\%$ & $100 \%$ & $100 \%$ & $>0.999$ \\
\hline Operative time & Mean \pm SD minutes per puncture & $29 \pm 8$ & $24 \pm 9$ & $<0.01$ \\
\hline Exposure time & Mean \pm SD minutes per puncture & $10 \pm 3$ & $8.8 \pm 3.4$ & $<0.05$ \\
\hline Cone-beam CT exposure dose & Mean \pm SD mGy & $352 \pm 173$ & $155 \pm 83$ & $<0.01$ \\
\hline No. of Cone-beam CT & Mean(Range/Median) & $2.1(0-4 / 2)$ & $0.9(0-2 / 1)$ & $<0.01$ \\
\hline IVR-CT exposure dose (DLP) & Mean \pm SD mGy & $656 \pm 331$ & $617 \pm 306$ & 0.323 \\
\hline No. of IVR-CT & Mean(Range/Median) & $1.1(1-3 / 1)$ & $1.2(1-2 / 1)$ & 0.062 \\
\hline Uni-or bilateral puncture & No. of uni-/bilateral puncture & $133 / 158$ & $49 / 38$ & 0.082 \\
\hline Bone cement volume & Mean(range/median) $\mathrm{mL}$ per vertebra & $1.6(0-7 / 1.4)$ & $1.8(0.4-6 / 1.6)$ & $>0.999$ \\
\hline Bone cement leakage & No. and (\%) of vertebra & $168(58 \%)$ & $62(71 \%)$ & 0.194 \\
\hline Pulmonary emboli & No. and (\%) of pts & $3(2 \%)$ & $0(0 \%)$ & 0.697 \\
\hline Cardiac dysfunction & No. and (\%) of pts & $3(3 \%)$ & $0(0 \%)$ & 0.818 \\
\hline NRS score before PVP & Mean \pm SD & $6.4 \pm 3$ & $6.6 \pm 3$ & 0.818 \\
\hline NRS score at 7 th day & Mean \pm SD & $2.3 \pm 2.4$ & $2.8 \pm 2.1$ & 0.71 \\
\hline ADL score before PVP & Mean \pm SD & $2.7 \pm 1.3$ & $2.8 \pm 1.4$ & 0.962 \\
\hline ADL score at 7 th day & Mean \pm SD & $1.5 \pm 1$ & $1.4 \pm 1$ & 0.765 \\
\hline
\end{tabular}

$S D$ standard deviation, $C T$ computed tomography, DLP dose length product, IVR-CT interventional computed tomography, No. number, Pts patients, $N R S$ numeric rating scaling, $A D L$ activities of daily living

group. In the VETERAN group, the Cone-beam CT exposure dose was significantly lower (with the mean \pm SD being $352 \pm 173$ vs. $155 \pm 83 \mathrm{mGy}$, respectively, $p<0.01$ ), and the number of Cone-beam CT scans was smaller (with the mean (range/median) being $2.1(0-4 / 2)$ vs. $0.9(0-2 / 1)$ times, respectively, $p<0.01$ ), compared with the CAP group, while there were no differences observed in the IVR-CT exposure dose or the number of IVR-CT scans.

No difference was observed between the two groups in the number of uni- or bilateral puncture, bone cement volume, the development of bone cement leakage, pulmonary embolism, cardiac dysfunction, pain NRS, or mobility ADL.

\section{Discussion}

In addition to ISOP method and CAP method, the bull'seye modification method, the angle fixation method using fluoroscopy, or CT-guided puncture have been proposed to improve the accuracy of the vertebral puncture in PVP $[2,8,9,23,24]$. All of the several PVP puncture methods have advantages and challenges. The bull's-eye modification method is to insert the needle so that it is viewed on-end via fluoroscopy so as to ensure straightness in the insertion direction. This is the basic needling method performed using fluoroscopy and it is easy to implement. However, this does not help determine the puncture course. The fixed angle insertion method involves inserting the needle at a fixed angle (15-25 degrees) and puncturing from the outside to the inside of the vertebral pedicle in the anterior-posterior fluoroscopic view. This method is also simple, but it limits the direction at which the needle can be inserted. CT-guided puncture can assist the safe and accurate puncturing into the vertebra, but the CT device is occupied for PVP for 2 to $3 \mathrm{~h}$. Anyway, there is no reliable CT-based safety assessment for PVP vertebral puncture with any method.

Numerous studies have been reported in orthopedics regarding the safety assessment of the pedicle screw placement. Aoude AA et al. conducted a systematic review of pedicle screw placement accuracy in spine surgery. They reported that the freehand or fluoroscopic techniques and navigation had the averaged accuracies of $91.4 \%$ and $97.3 \%$, respectively, for Grades A and B pedicle screws placement estimated using Gertzbein and Robbins classification scores [25]. In our study, Grades A and B needle punctures in CAP and VETERAN groups were $97.8 \%$ and $100 \%$, respectively, which both methods might have "clinically acceptable" accuracies of the vertebral punctures. In particular, VETERAN method significantly had the effect of reducing the "inaccurate" vertebral puncture as well as shortening the operative and exposure times per puncture compared with CAP method. This is because VETERAN method did not use Cone-beam CT to plan the puncture route before puncturing. Therefore, we recommend VETERAN method when puncturing the vertebrae using the fluoroscopy technique.

The ranges of the puncture angles with medial and lateral breaches both were overlapped with those of Grade A puncture angle in CAP and VETERAN groups combined in our clinical results shown in Table 3. Therefore, the puncture 
angle might not be always a good indicator of safe vertebral puncture.

According to our results shown in Table 4, there were no cases of medial cortical breaches when the VET-ratio was $36 \%$ or less, but there were some cases of medial cortical breaches when the VET-ratio was 37-50\%. A VET-ratio of over $50 \%$ could be dangerous in all cases in response to the medial cortical breaches. Therefore, $36 \%, 37 \%$ and $50 \%$ have been defined as the bounds for safe, cautionary, or dangerous VET ratios, respectively. These bounds of VET-ratio might help prevent the spinal canal intrusion. On the other hand, the safe lower limit of VET-ratio was difficult to determine in our results. It is necessary to find another index related to lateral cortical breaches in the further investigation. In addition, VETERAN has a potential risk of human error because it is judged only by visual measurement. Puncture training is indispensable to avoid this risk.

Our leakage rates (CAP: 58\%, VETERAN: 71\%) did not exceed $72-91 \%$ reported in previous articles [26, 27]. However, further measures such as improved cement properties or the injection volume rates should be considered to reduce the leakage.

Various leading-edge puncture support devices have been developed. Xu HT et al. proposed a navigation system that supported correct puncturing in PVP working with the $\mathrm{C}$-arm tracker, patient tracker, and puncture needle tracker adjusting the spinal image information [28]. Wang $\mathrm{B}$ et al. proposed a method for guiding punctures in Balloon kyphoplasty (BKP) using a system consisting of a reference tracker, a robotic arm, and a monitor [29]. As a unique attempt, the 3D-printer was used to create a puncture guide adapter for PVP, which had two sockets for inserting needles [30]. Those puncture methods are promising methods and further development is desired in the future.

This study has some limitations. VET-ratio was not measured on the actual fluoroscopic images. The effectiveness of visual VET-ratio on a real-time fluoroscopy has not been investigated. This study was performed in a retrospective fashion with a small number of punctures. The difference in skill levels among the operators was not considered. A prospective study involving relatively uniform experts and a large number of patients is desired.

In conclusion, this was the first study to determine the accuracy of vertebral puncture to help establish quality standards of the vertebral puncture in percutaneous vertebroplasty. The accuracies of vertebral punctures by CAP and VETERAN methods accounted for $97.8 \%$ and $100 \%$ of within safe zone (cortical breaches within $2 \mathrm{~mm}$ ), respectively, indicating that both had "clinically acceptable" accuracies according to Gertzbein and Robbins classification scores. VETERAN method had the significant benefits of shortening the operative and exposure times and reducing the occurrence of the inaccurate vertebral puncture compared with CAP method. In the case of vertebral puncture by VETERAN method, safe puncture is possible with a VET-ratio of $36 \%$ or less, caution is required with a VET ratio of $37 \%$ or more, and VET ratio must not exceed $50 \%$ during puncture.

Acknowledgements This work was supported in part by Department of Clinical Research, National Hospital Organization Kyushu Medical Center.

Author contributions TN data analysis, paper writing, corresponding author, KY paper correction, YS data collection, TO data collection, RK data collection, JM paper correction, TT supervision.

Funding No funding.

\section{Declarations}

Conflict of interest The authors wish to confirm that there are no known conflicts of interest associated with this publication and there has been no significant financial support for this work that could have influenced its outcome.

Ethical approval This study was approved by the Ethics Review Board of our hospital, which waived the need for written informed consent from the patients.

Open Access This article is licensed under a Creative Commons Attribution 4.0 International License, which permits use, sharing, adaptation, distribution and reproduction in any medium or format, as long as you give appropriate credit to the original author(s) and the source, provide a link to the Creative Commons licence, and indicate if changes were made. The images or other third party material in this article are included in the article's Creative Commons licence, unless indicated otherwise in a credit line to the material. If material is not included in the article's Creative Commons licence and your intended use is not permitted by statutory regulation or exceeds the permitted use, you will need to obtain permission directly from the copyright holder. To view a copy of this licence, visit http://creativecommons.org/licenses/by/4.0/.

\section{References}

1. Mathis JM, Deramond H, Belkoff SM. Percutaneous vertebroplasty and kyphoplasty. New York: Springer; 2006.

2. Baumann C, Fuchs H, Kiwit J, Westphalen K, Hierholzer J. Complications in percutaneous vertebroplasty associated with puncture or cement leakage. Cardiovasc Intervent Radiol. 2007;30(2):161-8.

3. Lim JB, Park JS, Kim E. Nonaneurysmal subarachnoid hemorrhage: rare complication of vertebroplasty. J Korean Neurosurg Soc. 2009;45(6):386-9.

4. Tropeano MP, La Pira B, Pescatori L, Piccirilli M. Vertebroplasty and delayed subdural cauda equina hematoma: Review of literature and case report. World J Clin cases. 2017;5(8):333-9.

5. Giordano AV, Arrigoni F, Bruno F, Carducci S, Varrassi M, Zugaro L, et al. Interventional radiology management of a ruptured lumbar artery pseudoaneurysm after cryoablation and vertebroplasty of a lumbar metastasis. Cardiovasc Intervent Radiol. 2017;40(5):776-9. 
6. Puri AS, Colen RR, Reddy AS, Groff MW, DiNobile D, Killoran $\mathrm{T}$, et al. Lumbar artery pseudoaneurysm after percutaneous vertebroplasty: a unique vascular complication. J Neurosurg Spine. 2011;14(2):296-9.

7. Umeda A, Saeki N, Matsumoto C, Nakao M, Kawamoto M. Abdominal aortic injury during vertebroplasty. Spine (Phila Pa 1976). 2015;40(7):E439-41.

8. Takizawa K, Yoshimatsu M, Nakajima Y, Sakaino S, Yagihashi K, Ogawa Y, et al. Development of a new support method for transpedicular punctures of the vertebral body: the isocenter puncture method. Cardiovasc Intervent Radiol. 2007;30(4):757-60.

9. Appel NB, Gilula LA. "Bull's-eye" modification for transpedicular biopsy and vertebroplasty. AJR Am J Roentgenol. 2001;177(6):1387-9.

10. Kamei S, Noguchi T, Shida Y, Okafuji T, Yokoyama K, Uchiyama F, et al. The safety and efficacy of percutaneous vertebroplasty for patients over 90 years old. Jpn J Radiol. 2019;37(2):178-85.

11. Noguchi T, Shida Y, Okafuji T, Kamei S, Yokoyama K, Uchiyama F, et al. Safety and efficacy of percutaneous vertebroplasty in lateral decubitus position: a retrospective evaluation. Interv Radiol. 2018;3(3):115-20.

12. Shida Y, Noguchi T, Okafuji T, Murakami K, Iraha T, Yokoyama $\mathrm{K}$, et al. Percutaneous vertebroplasty for acute osteoporotic vertebral fracture contributes to restoration of ambulation. Interventional Radiol. 2017;2(3):74-8.

13. Kobayashi N, Numaguchi Y, Fuwa S, Uemura A, Matsusako M, Okajima Y, et al. Prophylactic vertebroplasty: cement injection into non-fractured vertebral bodies during percutaneous vertebroplasty. Acad Radiol. 2009;16(2):136-43.

14. Fujiwara S, Kasagi F, Masunari N, Naito K, Suzuki G, Fukunaga M. Fracture prediction from bone mineral density in Japanese men and women. J Bone Miner Res. 2003;18(8):1547-53.

15. Tanigawa N, Komemushi A, Kariya S, Kojima H, Shomura Y, Omura N, et al. Relationship between cement distribution pattern and new compression fracture after percutaneous vertebroplasty. AJR Am J Roentgenol. 2007;189(6):W348-52.

16. Klotzbuecher CM, Ross PD, Landsman PB, Abbott TA 3rd, Berger M. Patients with prior fractures have an increased risk of future fractures: a summary of the literature and statistical synthesis. J Bone Miner Res. 2000;15(4):721-39.

17. Gailloud P, Beauchamp NJ, Martin JB, Murphy KJ. Percutaneous pediculoplasty: polymethylmethacrylate injection into lytic vertebral pedicle lesions. J Vasc Interv Radiol. 2002;13(5):517-21.

18. Gertzbein SD, Robbins SE. Accuracy of pedicular screw placement in vivo. Spine (Phila Pa 1976). 1990;15(1):11-4.

19. Fan Y, Du Peng J, Liu JJ, Zhang JN, Liu SC, Hao DJ. Radiological and clinical differences among three assisted technologies in pedicle screw fixation of adult degenerative scoliosis. Sci Rep. 2018;8(1):890.
20. Buchbinder R, Osborne RH, Ebeling PR, Wark JD, Mitchell $\mathrm{P}$, Wriedt $\mathrm{C}$, et al. A randomized trial of vertebroplasty for painful osteoporotic vertebral fractures. N Engl J Med. 2009;361(6):557-68.

21. Yokoyama K, Kawanishi M, Yamada M, Tanaka H, Ito Y, Hirano $\mathrm{M}$, et al. Validity of intervertebral bone cement infusion for painful vertebral compression fractures based on the presence of vertebral mobility. AJNR Am J Neuroradiol. 2013;34(1):228-32.

22. Yanai H. Statcel-the useful addin forms on excel. 3rd ed. Tokorozawa (in Japanese): OMS Publications; 2011.

23. Brugieres P, Gaston A, Heran F, Voisin MC, Marsault C. Percutaneous biopsies of the thoracic spine under CT guidance: transcostovertebral approach. J Comput Assist Tomogr. 1990;14(3):446-8.

24. Renfrew DL, Whitten CG, Wiese JA, el-Khoury GY, Harris KG. CT-guided percutaneous transpedicular biopsy of the spine. Radiology. 1991;180(2):574-6.

25. Aoude AA, Fortin M, Figueiredo R, Jarzem P, Ouellet J, Weber MH. Methods to determine pedicle screw placement accuracy in spine surgery: a systematic review. Eur Spine J. 2015;24(5):990-1004.

26. Klazen CA, Lohle PN, de Vries J, Jansen FH, Tielbeek AV, Blonk $\mathrm{MC}$, et al. Vertebroplasty versus conservative treatment in acute osteoporotic vertebral compression fractures (Vertos II): an openlabel randomised trial. Lancet. 2010;376(9746):1085-92.

27. Firanescu CE, de Vries J, Lodder P, Venmans A, Schoemaker MC Smeet AJ, et al. Vertebroplasty versus sham procedure for painful acute osteoporotic vertebral compression fractures (VERTOS IV): randomised sham controlled clinical trial. BMJ. 2018;361:k1551.

28. Xu HT, Zheng S, Kang MY, Yu T, Zhao JW. A novel computer navigation model guided unilateral percutaneous vertebroplasty for vertebral compression fracture: A case report. Medicine. 2020;99(44):e22468.

29. Wang B, Cao J, Chang J, Yin G, Cai W, Li Q, et al. Effectiveness of Tirobot-assisted vertebroplasty in treating thoracolumbar osteoporotic compression fracture. J Orthop Surg Res. 2021;16(1):65.

30. Hu PL, Lin JS, Meng H, Su N, Yang Y, Fei Q. A novel "threedimensional-printed individual guide template-assisted percutaneous vertebroplasty" for osteoporotic vertebral compression fracture: a prospective, controlled study. J Orthop Surg Res. 2021;16(1):326.

Publisher's Note Springer Nature remains neutral with regard to jurisdictional claims in published maps and institutional affiliations. 